\title{
On Classroom Teaching Reform of Humanities and Social Sciences in Colleges and Universities in the New Era
}

\author{
Keke Du ${ }^{1, *}$, Yanhui Tian ${ }^{1}$, Shengjun Bai ${ }^{1}$, Junfei $\mathrm{Bi}^{1}, \mathrm{Zi}_{\text {Wang }}{ }^{1}$ \\ ${ }^{I}$ College of Information and Communication, National University of Defense Technology, Xi'an, Shaanxi, China \\ *48059821@qq.com
}

\begin{abstract}
To promote the teaching reform and innovation of humanities and social sciences in colleges and universities in the new era, it is necessary to have a deep understanding of the special importance of their courses, and to make great efforts to build a "four-degree" class with high level, depth, temperature and effectiveness, constantly improve the ideological, theoretical and affinity of classroom teaching, targeted, truly make it become a life-long benefit to students, life-long unforgettable quality courses.
\end{abstract}

Keywords: the new era, humanities and social sciences, teaching reform.

\section{新时代高校人文社会科学课堂教学改革刍议}

\author{
杜柯柯 ${ }^{1}$ * $^{*}$ 田艳辉 ${ }^{1}$ 白胜军 ${ }^{1}$ 毕俊菲 1 王紫 1 \\ ${ }^{l}$ 国防科技大学信息通信学院, 西安, 陕西, 中国 \\ *48059821@qq.com
}

\section{摘要}

推进新时代高校人文社会科学教学改革创新, 要深刻认识其课程的特殊重要性, 在打造有高度、有深度、有温 度、有效度的 “四度” 课堂上下功夫, 不断提升课堂教学的思想性、理论性和亲和力、针对性, 真正使其成为 学生终身受益、毕生难忘的优质课程。

关键词: 新时代; 人文社会科学; 教学改革

\section{1.前言}

高等教育是一个国家发展的重要动力和源泉, 其 质量高低不仅影响个人的成长成才, 还显著影响着国 家整体人才培养水平, 对国家的经济建设、社会发展、 科技创新等方面起到重要的推动作用。近年来, 高校 人文社会科学课程建设进一步规范, 教师队伍教学能 力不断提升, 课堂教学效果明显改善, 学生获得感不 断增强。同时, 也必须清醒地认识到, 目前课程教学 中仍一定程度存在学生到课率低、课堂亲和力差, 教 师 “单打独斗”、教学陷于 “孤岛化” 窘境, 培养人文 素养与专业素质协同性弱等问题。由此, 高校人文社 会科学教学改革必须强化问题导向, 弘扬改革创新精 神, 扭住短板破解难题, 不断加强课程教学的思想性、
理论性, 提升其亲和力、针对性, 真正使其成为学生 真心喜爱、终身受益的 “金课”。本文以高校人文社会 科学为研究对象, 分析了其课堂教学改革的重要意义, 科学探究了当前人文社会科学课堂教学中存在的问 题, 并针对性地探讨了推动高校人文社会科学课堂教 学改革创新的思路与对策。

\section{2. 高校人文社会科学课堂教学改革的意义}

\section{1 课堂教学改革是提升人文社会科学学习 效果的必然要求}

人文社会科学从定义上解释, 它是人文科学和社 会科学的总称, 是有关于人类的思想、认识、文化、 
教育、社会现象、社会发展等方面的学科, 主要研究 和阐释人类文化、人类关系, 以及各种社会现象及其 发展规律。人文社会科学主要通过一定的思想理论和 技术方法，对现有的人类关系、人类活动和社会现象 进行分析研究, 并在此基础上进行总结归纳, 最终发 现和解释其内在本质、逻辑关系和发展趋势, 从而为 有效促进社会的发展和人类的进步提供合理化的建 议。综上可见, 人文社会科学是与社会现象、人类关 系、人类活动、人类文化以及社会发展密不可分的, 如果脱离了社会实际, 课程教学就失去了其存在的意 义。因此, 推动高校人文社会科学课程课堂教学改革 是人才培养和学科教育教学的必然要求。

\section{2 课堂教学改革是促进学生理论联系实际 的有效举措}

目前, 人文社会科学的课堂教学主要是以教师的 理论说教和学生的被动学习相结合的传统教学模式 为主, 与之相比较, 思想性与理论性相融合、亲和力 与针对性相促进、理论学习与实践教学相结合、培养 人文素养与专业素质相协同, 显然是一种更为高效的 学习方式。重视课堂教学改革, 实际上就是为学生提 供从多个角度进行理论知识学习的机会。通过课程教 学内容和形式的改革创新, 学生能够对所学习的理论 观点和知识技能进行多角度全方位的理解和掌握。比 如, 学生能够灵活应用自己所学的知识技能, 解决现 实生活中遇到的实际问题, 从而更为全面深刻地理解 掌握课堂所学的理论知识。课程教学在思想性、理论 性、亲和力、针对性等方面的增强, 不仅能够让学生 的学习过程更加丰富, 还能在提升学生学习兴趣的同 时, 增强学习和掌握理论知识的效率和效果。浓厚的 学习兴趣能够积极调动学生自身的主观能动性, 从而 进一步提高学习效率。

\section{3 课堂教学改革是激发教师教研探索精神 的重要途径}

在人文社会科学的教师队伍中, 确有部分教师缺 乏课堂探索精神, 教学中存在依纲靠本、照猫画虎、 得过且过的现象。探索是良好教育的当然要素: 探索 意味着探索者不因循守旧、墨守成规, 意味着探索者 的大胆尝试、追求卓越, 意味着探索者经验的开放性 和工作中丰富的动机。教师成为研究者, 不仅要研究 教学的内容, 做课程的开发者, 同时要探索有效教学 的策略, 探索如何创设情境和氛围, 如何设计教学的 活动, 如何搭建师生、生生之间交流的平台, 如何构 筑研究性学习的支持系统, 如何评价学习的效果等等, 因为探索使得课堂多一份灵动与飞扬, 多一些朝气与 活力。教师的探索精神影响、引领和激励着学生的探 索欲望, 课堂生活因为探索而变得悬念迭起、趣味无 穷, 变得开放、幽深、鲜活和鬼米力十足, 因为师生的 共同探索, 而享有着更高品质的学校生活。

\section{3. 高校人文社会科学课堂教学的现状分析}

\section{1 注重 “作料”, 疏于 “入味”}

高校人文社会科学的课堂教学始终坚持正确的 政治方向，体现了 “教书育人、立德树人” 的根本属 性。但是, 人文社会科学课程的政治性并非孤立存在 的，政治性犹如 “作料”，而思想性犹如 “食物”，只 有将二者有机结合、恰当搭配、紧密渗透在一起才能 达到理想的育人效果。正如习近平总书记在全国高校 思想政治工作会议上所强调的，“好的思想政治工作 应该像盐, 但不能光吃盐, 最好的方式是将盐溶解到 各种食物中自然而然吸收。”然而, 当前教学实践中, 一些高校的人文社会科学课程教学陷入 “低水平重 复”, 教师成为 “照着讲” 的 “复读机”, 理论讲授仅 限于 “是什么” “有何意义”, 学生只 “知其然”, 而不 “知其所以然”。

\section{2 注重 “树冠”，疏于 “楖根”}

高校人文社会科学课程的内容体系犹如一棵大 树, 教学过程中不仅要关注其树梢和树冠, 更要探究 其树干和树根。比如, 很多教师在论证观点时习惯于 使用举例说明、现身说法的方式, 这种形象化的教学 方式是增强理论讲授说服力的必要条件, 但并非充要 条件。在阐述理论时, 往往只是一鳞半爪、一知半解, 仅仅停留在经验、感受、情感的层面, 学理分析不够 透彻, 思想理论不够彻底, 思维引导不够科学, 从而 无法真正回应学生、说服学生、引导学生, 使得课程 教学未能实现思想性与学理性相统一、价值性与知识 性相统一。

\section{3 注重“传其道”, 疏于“亲其生”}

良好的师生关系是达到理想育人效果的前提。对 学生而言, “亲其师则信其道”, 而对于教师而言, 就 是 “亲其生则传其道” 。人文社会科学中大部分课程 是面向高校各专业学生的基础课和公共课, 由于课程 的特殊性, 师生配比基数一般都比较大, 往往采取 “大 班授课” 的模式, 这就导致很多课程在师生关系和情 感互动上区别于小班教学的专业课。理论传授的 “高 冷” 加上现实生活中师生主动或者被动的 “失联”, 导 致教师难以准确把握学生的学习、思维和生活实 际, “亲其生” 不够, 使得课程教学的实效性大打折 扣。同时, 学生与教师在日常学习生活中缺乏亲近感, 这种情感距离也一定程度上影响了他们对课程的接 受度和获得感。

\section{4 注重“覆盖面”, 疏于“精准度”}

长期以来, 人文社会科学理论课教学注重及时跟 踪创新理论发展步伐, 积极推进社会科学理论前沿 “系统进教材、生动进课堂、扎实进头脑”, 理论教学 
的深度和广度不断拓展。但是, 由于缺乏问题导向, 有 些时候无法找出针对面和关切点实施教学, 因此, 在 解答学生真实困惑、回应学生现实关切、满足学生成 长需求的精细化和精准度上, 还有不少提升的空间。 当前人文社会科学理论教学实践中,一定程度上还存 在理论讲授照本宣科、人云亦云, 答疑释惑语焉不详、 浅尝轩止等现象, 使教学仅仅停留在理论宣讲和观点 阐述上, 无法深入到现实问题和思想的层面, 无法回 应学生的现实关切和深层疑惑。

\section{4.推进高校人文社会科学课堂教学改革创新 的思考}

推进新时代高校人文社会科学课堂教学改革创 新, 要着力提升其思想性、理论性和亲和力、针对性, 努力打造有高度、有深度、有温度、有效度的 “四度” 课堂, 真正使人文社会科学课程成为学生真心喜爱、 终身受益、毕生难忘的优质课程。

\section{1 要“言之有物”, 让课堂更有“高度”}

理论性是人文社会科学课程的本质属性, 而思想 性是其首位要求, 只有将二者有机融合、紧密渗透, 才 能让人文社会科学课堂教学真正做到 “言之有物”, 实现 “用彻底的思想理论说服学生, 用真理的强大力 量引导学生”。为此, 需要在以下两个方面努力: 一方 面要拓宽视野。人文社会科学专业教师 “视野要广, 要有知识视野、国际视野、历史视野, 通过生动、深 入、具体的纵横比较, 把一些道理讲明白、讲清楚”。 通过深入研究教学内容拓宽视野, 教师就可以变 “照 本宣科” 为 “融会贯通” “精辟讲解”, 就可以变教导 学生 “知其然” 为引导学生 “知其所以然”, 就可以 在讲清楚 “是什么” “有何意义” 的基础上讲明白 “为 什么” 和 “怎么样”, 就可以在古今中外, 应然实然比 较的基础上自然而然地引出科学的结论。另一方面要 教研相长。围绕教学内容开展深入踏实的科研工作, 是避免人文社会科学课堂教学沦为 “低水平重复”, 增强其思想性的必要途径。只有树立 “教研相长” 的 意识在深入研究教学内容的基础上讲出思想性, 以科 学研究的标准保证课堂教学的质量, 变 “空洞无物” 为 “言之有物”, 才能真正提升学生课堂教学的获得 感。

\section{2 要“鞭辟入里”, 让课堂更有“深度”}

马克思曾说“理论只要说服人, 就能掌握群众; 而 理论只要彻底, 就能说服人。”理论性是增强人文社会 科学课堂教学说服力的必然要求。理想信念的坚定离 不开对科学理论的认同, 信仰之基须由深厚的学理来 筑牢。而真正的说服力来自于理论的科学性和系统性。 一要把握理论讲授的科学性。教学过程中, 不能仅仅 采用 “观点+事例” 的方式说明问题, 而要从思维抽 象的角度深刻解析问题。如, 讲授我国改革开放所取 得的伟大成就, 不能只是以单纯举例的方式展现成就,
还要从制度机理的角度讲清产生伟大成就的原因。二 要把握理论讲授的系统性。具体而言: 讲授历史史实, 要讲清楚事件的前因后果; 讲授政策法规, 要讲清楚 条文规定、背景实质和实施重难点; 讲授理论原则, 要讲清楚其最终样态、来龙去脉和时代内涵。如, 讲 授军队政治工作的地位作用, 就要讲清楚 “政治工作 是军队生命线” 的科学内涵, 讲清楚这一论断提出的 理论依据和现实依据, 讲清楚 “政治工作是军队生命 线” 论断在国防和军队建设进入新时代的时代内涵。 只有在讲授过程中对教学内容做到深刻而系统的阐 述, 才能变 “蜻蜓点水” 为 “鞭辟入里”, 让人文社 会科学的课堂更有内涵、更有深度。

\section{3 要“面目可亲”, 让课堂更有“温度”}

人文社会科学的课堂既要有思想的高度、理论的 深度, 还要有情感的温度, 正所谓 “亲其师, 才能信其 道” “亲其生, 才能传其道”。亲和力让人文社会科 学的课堂有了 “温度”, 所以才能播撒下真善美的种 子, 温暖人性、启迪人心、指引方向。

增强教学的亲和力, 一要强化师生平等意识。教 师与学生角色不同、职责不同, 但人格尊严和社会地 位是平等的。要坚持 “教学相长” 的理念和 “师生相 友” 的做法, 一方面充分尊重和保护学生的积极性、 主动性和创造性, 关注学生的接受程度和反馈意见, 真诚地向学生学习借鉴; 另一方面要加强师生互动交 流, 了解学生的真实困惑, 回应学生的现实关切, 用教 师的人格魅力让课堂变得更加可亲。二要调整话语体 系。善于运用大众话语、网络语言, 把理论话语、学术 话语转化为通俗、亲切的表达, 对理论内容进行通俗 的阐释和生动的表述。近些年, 习近平总书记在新年 贺词中妙语连珠地使用了 “撸起袖子加油干” “天上 不会掉馅饼” “小康路上一个都不能掉队” 等网络热 语, 这些语句文风朴实、娓娓道来、深入人心、情真 意切, 令人印象深刻。这种 “接地气” 的话语方式, 在 人文社会科学的课堂教学中是值得学习和借鉴的。要 让学生接受教学内容背后支撑的理论观点和价值观 念, 首先得让他们接受课堂教学的表达方式。放下理 论讲授 “高大上” 的身段, 人文社会科学的课堂在教 学形式上才能更有说服力。三要增强教学互动。实践 教学是理论教学在课堂之外的延伸、拓展和升华, 使 学生在实践体验感知中完成自我知识建构, 培养其知 识迁移及应用能力。在教学中创设理论联系实际的情 景, 广泛运用研讨交流、互动问答、课堂辩论、线上互 动、线下体验等形式, 促进学生通过汲取理论养分、 感悟实践历练, 增强对人文社会科学课堂教学的亲近 感和趋同感。

\section{4 要“有的放矢”, 让课堂更有“效度”}

针对性是思想性、理论性和亲和力实现的落脚点, 是人文社会科学课堂教学的生命力所在。缺失明确的 指向性即针对性, 人文社会科学的课堂教学将如同 
“盲人骑瞎马、夜半临深洲”, 就有迷失方向、落后 于时代的危险。

增强针对性, 关键要强化问题导向, 找准针对面 和关切点实施教学, 在 “大水漫灌” 的同时强化 “精 准滴灌”。一要针对学生困惑 “推陈出新”。优质的课 堂必须要解决学生的疑惑。对于学生的现实困惑, 教 学中不能视而不见、置之不理, 而应该直面问题、认 真剖析, 通过互动交流、研讨启发、案例分析、情景体 验等形式, 进行学理上的科学分析与精准阐释。课堂 上, 学生提出了 “公有制和私有制比较起来, 似乎私 有制效率更高啊? ”针对学生的这一疑惑, 作为教师 可以首先提出 “私有制真的效率更高吗？” “人类文 明发展的最终走向是贫富悬殊? 还是共同富 裕?” “私有制能够让中国实现共同富裕吗? ”等 一系列问题, 通过问题导向, 进行详细剖析讲解, 让 学生逐渐认识到私有制的本质矛盾和根本缺陷, 了解 盲目照搬西方私有化给部分国家带来的灾难, 以此让 学生产生 “推陈出新” 后的获得感。二要针对思想误 区 “破立结合”。人文社会科学的理论教学 “要坚持建 设性和批判性相统一” 的原则, 即教学过程中不仅要 “立”, 而且要 “破”, 不仅要及时跟进理论创新发展 步伐, 而且要敢于批驳错误观点和思潮。如, 在讲解 社会主义的本质理论时, 融入对 “质疑中国特色社会 主义的社会主义性质” 思潮的批驳, 帮助学生纠正错 误观点, 澄清模糊认识。三要针对育人需求 “有的放 矢”。立德树人是高校人文社会科学培养目标的中心 环节, 要围绕学生成长成才需求, 建立增长知识、提升 能力、培塑情感、引领价值的教学目标体系, 因地制 宜、因时制宜、因材施教, 增强学生对人文社会科学 的理论认同、情感认同和价值认同, 让课程教学对于 人才培养更加 “切实管用”。

\section{5.结论}

高等教育的质量效果关系到整个民族、国家和社 会的发展进步, 高校的课堂教学质量关系到人才培养 的质量和效率, 因此, 其重要性不言自明。高校人文 社会科学课程是培养德才兼备的高素质、专业化新型 人才的基础性课程, 关键性课程。提升人文社会科学 课程教学的实效性, 不是一蹴而就、一劳永逸的, 而 是需要厚积薄发、与时俱进、不解努力的。着力打造 有高度、有深度、有温度、有效度的 “四度” 课堂, 是提升人文社会科学课程教学效果的有效着力点。只 有充满思想高度和理论深度的内容, 才能让课程本身 充满温度和热度, 才能让学生感受亲和力、增强获得 感, 才能持续、长久地提升高校人文社会科学课程教 学的实效性。

\section{REFERENCES}

[1] Tang, H.J., Shen, C.(2020) On the construction of the dialogue between the classics and the practice, the theory and the reality — A preliminary exploration of the reform of the classroom teaching of Marxist journalism. J. Teaching in Chinese universities., 12:66-69.

[2] Kong, J.(2020) Exploring the reform of classroom teaching and constructing characteristic subject courses. J. People's education., 19:48-51.

[3] Wang, L.M.(2014) The application of experimental teaching mode in humanities and social science teaching. J. Heilongjiang higher education research.,11:178-181.

[4] Yang, X.L., Cheng, Y., Yang, Q.S.(2018) An empirical analysis of undergraduate classroom learning in a student-centered teaching model — A case study of humanities and social sciences in three universities in Heilongiiang. J. Heilongjiang higher education research.,11:89-93.

[5] Xu, J.G., Liu, Y.(2020) Practice and exploration of "Trinity" teaching reform in ideological and political theory course. J. Guide to ideological and theoretical education., 12:53-56.

[6] Bai, R.(2021) On-line and off-line teaching mode of ideological and political course in colleges and universities: practice and Improvement Path Taking the teaching practice of Shenyang University as an example. J. Journal of Shenyang University (Social Science Edition)., 2:245-248. 